\title{
A model research for prototype warp deformation in the FDM process
}

Tian-Ming Wang $\cdot$ Jun-Tong Xi $\cdot$ Ye Jin

Published online: 2 December 2006

(C) Springer-Verlag London Limited 2006

The online version of the original article can be found at http://dx.doi. org/10.1007/s00170-006-0556-9.

T.-M. Wang $(\bowtie) \cdot J .-T$. Xi $\cdot$ Y. Jin Institute of Computer Integrated Manufacturing,

School of Mechanical and Power Engineering,

Shanghai Jiaotong University,

Room 1205, HaoRan Building, No. 1954, HuaShan Road,

Shanghai 200030, People's Republic of China

e-mail: wangtianming@sjtu.edu.cn

J.-T. Xi

e-mail: jtxi@sjtu.edu.cn

Y. Jin

e-mail: jinye@sjtu.edu.cn
The originally published reference list of this article unfortunately contained a mistake.

Incorrect reference:

Detlef K, Chua CK, Du ZH (1999) Rapid prototyping issues in the 21st century. Comput Ind 39(1):3-10

Correct reference:

Kochan D, Chua CK, Du ZH (1999) Rapid prototyping issues in the 21st century. Comput Ind 39(1):3-10 